\title{
S052042
}

\section{剥離抑制効果最大となる プラズマアクチュエータ間欠駆動条件の最適設計}

\author{
前田 健吾 ${ }^{* 1}$, 春名 賢一 ${ }^{* 1}$, 松野 隆 ${ }^{* 1}$, 金崎 雅博"2
}

\section{Optimal design for the drive conditions of}

\section{pulsed plasma actuator for separation control}

\author{
Kengo MAEDA $^{* 1}$, Kenichi HARUNA ${ }^{* 1}$, Takashi MATSUNO ${ }^{* 1}$ and Masahiro KANAZAKI ${ }^{* 2}$ \\ ${ }^{* 1}$ Tottori Univ. Dept. of Mechanical Engineering \\ Koyama 4-101, Tottori, Tottori, 680-0945 Japan \\ *2 Tokyo Metropolitan Univ. Dept. of Aerospace Engineering \\ Asahigaoka 6-6, Hino, Tokyo 191-0065 Japan
}

Development of the optimization system for aerodynamics control using plasma actuator has been conducted. The system which uses the Efficient Global Optimization method was designed to explore the optimum value with a small number of sampling. By using the current optimization system, the Lift maximization for bluff body using plasma actuator, with multiple design variables, was successfully carried out. The results of experiment that indicates the optimization method developed in this study is evaluated as effective and can reduce a numerous number of sampling during windtunnel experiment.

Key Words : Plasma actuator, Efficient global optimization, Wind tunnel test

\section{1. 緒言}

現在航空機の空力操舵や大きな揚力を得るため用いられているフラップやボルテックスジェネレータなどは, 複雑な 機構を必要としエネルギ効率が低いという問題点を持っており，これらに替わる新しい流体制御法の開発が期待されて いる.これに対して，誘電体バリア放電（Single Dielectric Barrier Discharge, SDBD）を利用したプラズマ流体アクチュエ 一タが近年注目されている. プラズマアクチュエータは, 機構が単純であり, 完全に電気的に駆動されるため時間応答 性がよいなど，様々な利点を持っている(1). 本研究室では，円柱等のブラフボディを対象にプラズマアクチュエータを 用いた流体制御手法を研究している. 剥離制御にはプラズマアクチュエータの間欠駆動が有効であり, 特定の周期・比

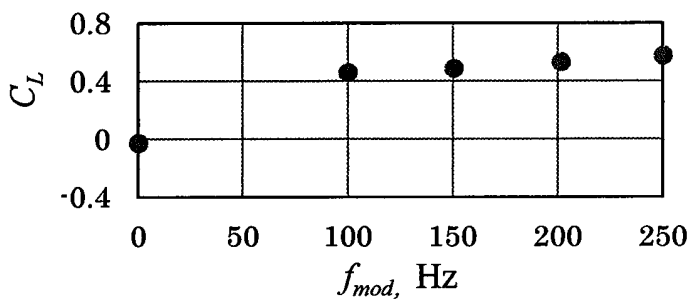

Fig.1 Change in lift coefficient due to modulation frequency of pulsed plasma actuator for circular cylinder model.
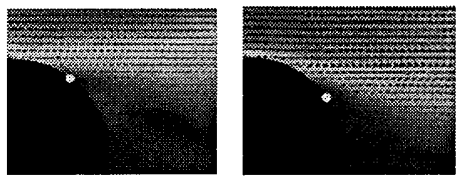

(a) off

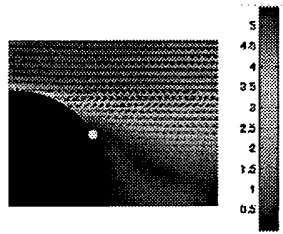

(c) $f_{\text {mod }}=200 \mathrm{~Hz}$

Fig. 2 Change in separation point at Duty Cycle $50 \%$.

\footnotetext{
*1 鳥取大学大学院 工学研究科（テ 680-0945 鳥取県鳥取市湖山町南 4-101）

*2 正員, 首都大学東京 システムデザイン学部 （テ191-0065 東京都日野市旭が丘 6-6）

E-mail: b081054@gmail.com
} 
率でプラズマアクチュエータを駆動することで剥離制御性能の向上が可能であることが分かっている(2). 円柱模型に 対

しては，片側の剥離位置を抑制することにより循環を付与し，揚力を向上することが可能である．図 1 に示すのは円 柱の剥離点近傍にプラズマアクチュエータを設置した際の間欠駆動の周波数 $f_{m o d}$ に対する揚力係数 $C_{L}$ の変化であるが, ここから $f_{\text {mod }}$ が高い条件で揚力が増加していることがわかる.またこの時の PIV 計測によって得られた剥離点近傍の速 度場 (図 2 参照) から，高い $f_{\text {mod }}$ において有効に剥離が抑制されていることが分かる.

一方で, プラズマアクチュエータの駆動に関する入力変数は数多く, さらに適用する流体問題やその条件によって最 適な構成および設定は変わる.このため, プラズマアクチュエータによる流体制御を適切に行うためには，相互に影響 する多数のパラメータについて最適な条件を設定する必要があるが，これは直感的な探索では極めて難しい．われわれ はプラズマアクチュエータの流体制御性能の最大化を目的として，Kriging 法と領域分割型 GA を組み合わせた Efficient Global Optimization (EGO) 法を利用したプラズマアクチュエータの駆動条件の最適化システムを構築した. 本 稿では構築した最適化システムをプラズマアクチュエータによるブラフボディの空力制御問題に適用し，実際に揚力を 最適化できることを実証しその有用性を確かめる.

\section{2. 実験装置および最適化手法}

本研究の風洞試験には鳥取大学所有の吸込型低速風洞（計測部 $600 \times 600 \mathrm{~mm}$ ）を用い，一様流速 $U_{\infty}=10 \mathrm{~m} / \mathrm{s}$ で実験を 行った． 実験装置概要を図 3(a) に示す．実験模型は図 3(b) のように直径 $105 \mathrm{~mm}$ の円柱を用いた.

ブラズマアクチュエータの電極には銅箔テープ (厚さ $275 \mu \mathrm{m}$ ), 誘電体には円柱模型のボディ (アクリル 厚さ $5 \mathrm{~mm})$

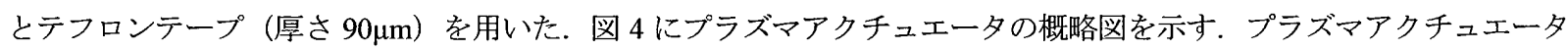
は円柱模型の澱点からの角度が $85 \mathrm{deg}$ となる位置に設置した. プラズマアクチュエータの駆動はPCに設置したアナロ グ出力ボードから原波形を生成し, 電力増幅器, 変圧器より電圧を増幅し交流高電圧を印加することにより行った. こ のとき設定できるプラズマアクチュエータのパラメータは交流電圧の振幅 $V_{a c}$ および周波数 $f_{a c}$ ，また PWM 駆動時の モジュレーション周波数 $f_{\text {mod }}$ および on/ off の割合であるデューティ比 $D C$ である. なお，本研究におけるプラズマア クチュエータの交流周波数 $f_{a c}$ は $11.5 \mathrm{kHz}$, 印加電圧 $V_{a c}$ は $22 \mathrm{kV}_{\mathrm{ac}}$ に固定した.

最適化手法は金崎らの研究によって有効性が示されている Efficient Global Optimization (EGO) $)^{[3-4]}$ 娄用いた. EGOによ る最適化プロセスを図 5 に示す. 本手法では，まずラテン方格法により初期サンプルの設計変数を決定し，風洞試験に より初期サンプルの評価值 $C_{L}$ を取得し，これを用いて kriging モデルを構築する. 次に，求められた初期モデルにおい て Expected Improvement (EI) 值が最大となるような設計変数を領域型遺伝的アルゴリズム (DGA) により求め，それを 次のサンプルとし，風洞試験により評価値を取得し，これを含んだ全サンプルによって kriging モデルを再構築する. このプロセスを評価值の改善が小さくなるまで繰り返す.

本研究の設計最適化はプラズマアクチュエータ非定常駆動時の円柱模型の揚力係数 $C_{L}$ の最大化問題であり, 設計変 数を間欠駆動時のパラメータ $f_{\text {mod }}$ および $D C$ の 2 変数とした. それぞれの設計範囲は $30 \leq f_{\text {mod }} \leq 200 \mathrm{~Hz}$ および $10 \leq D C \leq 65 \%$ とした. 初期モデルを生成するサンプル数は 8 とし，DGA の集団分割数を 4 , 各集団の個体数を 16 , 各 島の固体の移住間隔を 8 とし，60世代の探索を行った．また，本研究では，最適設計が正しく行われているか検証す るため比較対象としてパラメータ空間全体を網羅的に 144 点の空力計測を行った. 


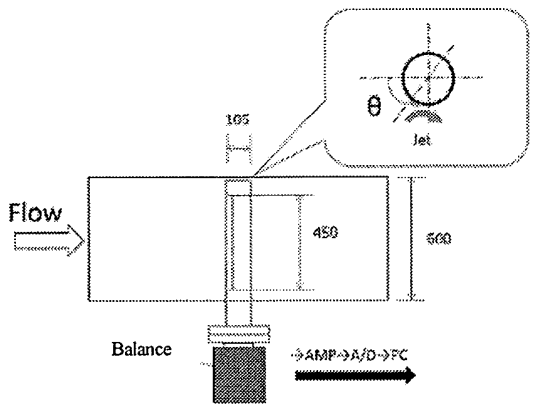

(a) Schematic drawings

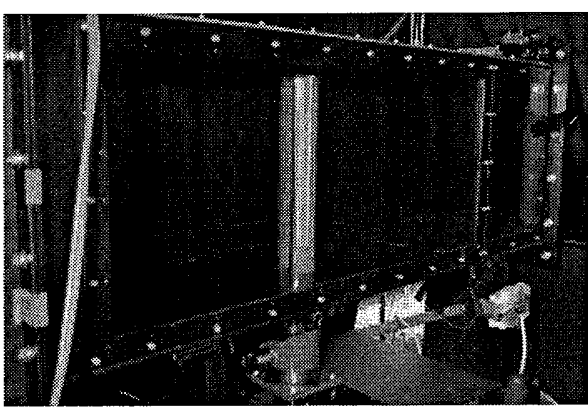

(b) Photograph of circular cylinder

Fig. 3 Schematic of the experimental setup.

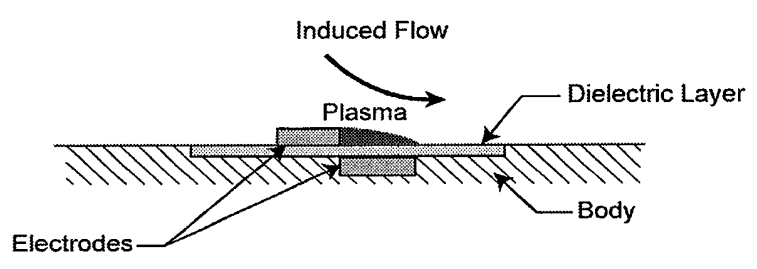

Fig. 4 schematic of SDBD Plasma actuator.

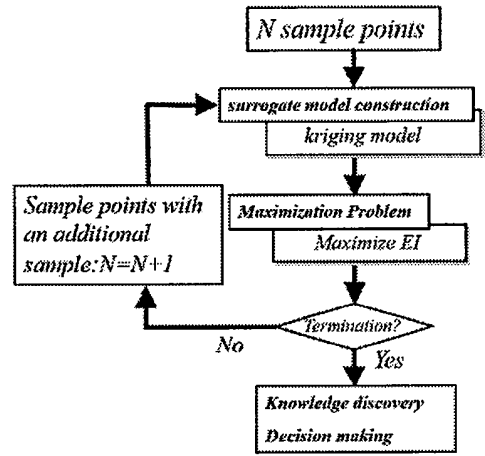

Fig. 5 Procedure of present design process.

\section{3. 結果および考察}

風洞試験を用いて最適化問題に対し設計変数を探索した結果を示す. なお本試験では, プラズマアクチュエータの駆 動条件について初期サンプル 8 点により，2 章で示した手順により最適化を行った結果，13 点のサンプルが追加され た.

まず，初期サンプル 8 点による kriging モデルの示す近似曲面と EI 值の等值線図を図 6 に示す．初期サンプルのみの 情報からは， $f_{\text {mod }}$ および $D C$ の低い領域で $C_{L}$ は小さく， $f_{\text {mod }}$ および $D C$ ともに高い領域で $C_{L}$ が大きいと示されてい る. デューティ比が高い場合，単純にプラズマアクチュエータの駆動時間が長く投入エネルギが大きいため，このよう な条件で $C_{L}$ が大きくなるのは直観的に妥当である． $\mathrm{EI}$ 值の等值線図をみると， $C_{L}$ 予測值が大きく，かつ初期サンプル の存在する点から離れた領域で EI 值が大きくなっている.このとき，DGA による EI 值最大化の結果，次の実験点は $f_{\text {mod }}=192.5 \mathrm{~Hz}, D C=64 \%$ と決定された.

EGO により指示されたサンプル点を順次追加していき，最終的に初期サンプルを含めて計 21 点の試験を行った後に 得られた近似曲面を図 7(a) に示す．当初の予測どおり，大域的には $f_{\text {mod }}$ および $D C$ がともに高い領域で大きい $C_{L}$ が得 られているが，最大 $C_{L}$ を示す点は $f_{m o d}=188.5 \mathrm{~Hz}$ および $D C=45.7 \%\left(C_{L}=0.119\right)$ とデューティ比最大の条件とはなら なかった. ここから，プラズマアクチュエータの効果は単純に投入エネルギのみに依存しているわけではないことがわ かる.

また，検証のためにあわせて行った網羅的に空力計測を行い得られた近似曲面を図 7(b) に示す.ただし，本実験の 全実験可能点 (サンプル点候補) は非常に多く, 全点の実験を行うことは現実的ではないため,ここに示した近似曲面 は，等閒隔に 144 点の実験条件を選択し風洞試験を行い，その結果を用いて kriging 法により設計空間全体の近似解を 計算したものである. この結果と EGOにより得られた近似曲面を比較すると, 高 $f_{\text {mod, }}$, 高 $D C$ で効果が大きく, その領 域内でも局所的に $C_{L}$ が大きい領域が存在する点など, EGOによって基本的な特性が正しく得られていることが確認で きる. 一方で, 今回の最適化の評価值には実験值を用いているため, 評価值は必ず実験的誤差を含む. これが $C_{L}$ 予測 值に影響しているため，近似曲面の詳細は誤差を含んでいると考えられる．㥶験值を用いた EGO を行う際には，実験 の精度や分散の評価について慎重に取り扱う必要がある. 


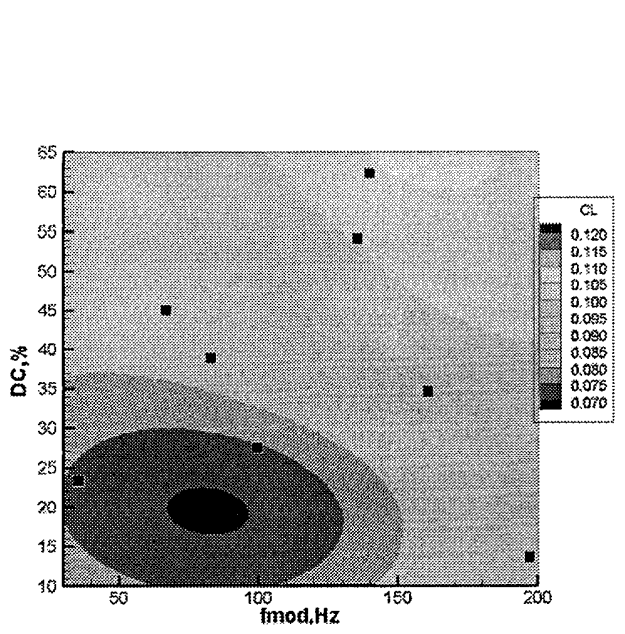

(a) Approximate response surface

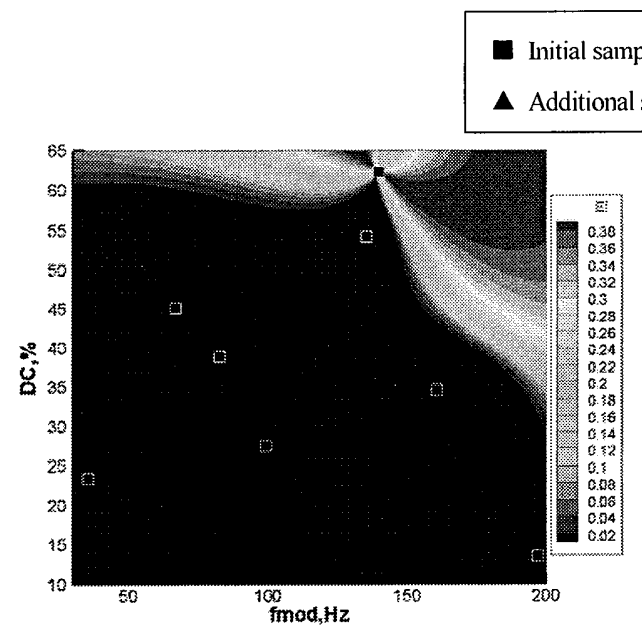

(b) Distributions of Expected Improvement value

Fig. 6 Sample points and contours obtained from Kriging model; for initial eight sample points.

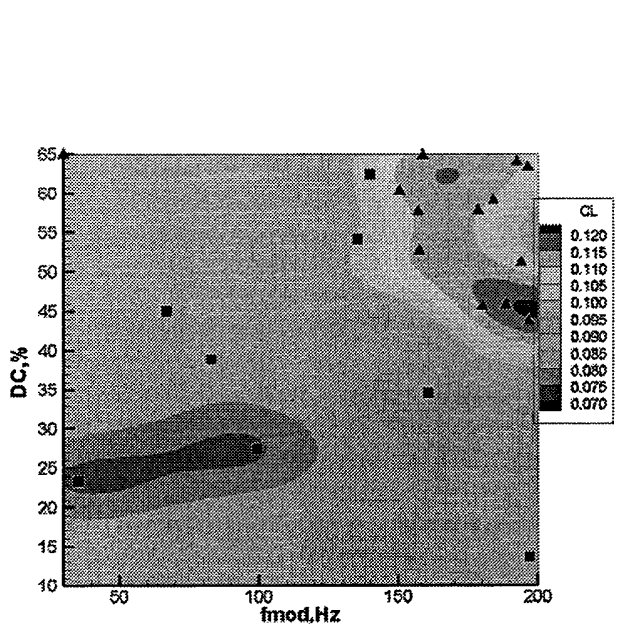

(A) Kriging model; with the final sample point

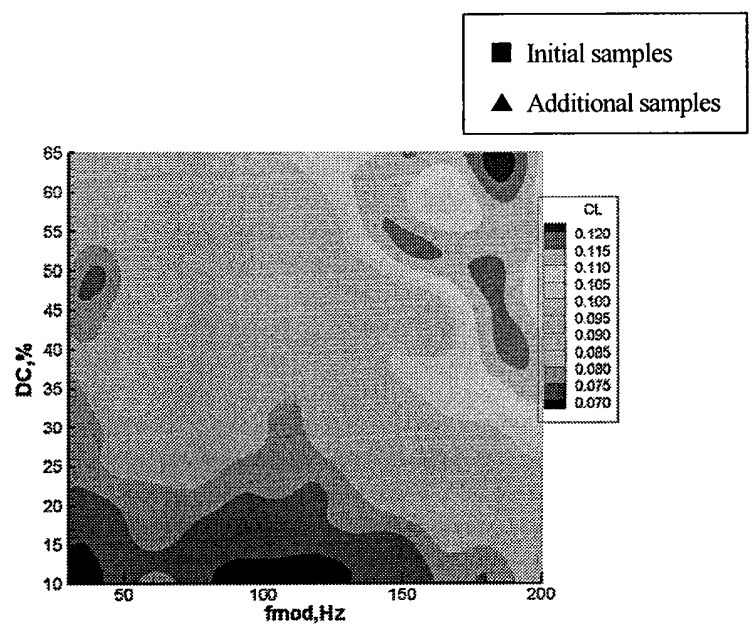

(B) Parametric study

Fig. 7 Approximate surface of lift coefficient. 


\section{4. まとめ}

プラズマアクチュエータを設置した模型に剥離制御最大効果を得る（ $C_{L}$ 最大となる）駆動条件の最適設計を行った. 得られた知見を以下にまとめる.

- EGOによりモジュレーション周波数とデューティ比の最適条件を探索した結果, 高い $f_{\text {mod }}$ および高い $D C$ に おいて $C_{L}$ が大きくなることが分かった。 この時の最適条件は $f_{\bmod }=188.5 \mathrm{~Hz}$ および $D C=45.7 \%$ で $C_{L}=0.119$ であった.

- EGO の結果とパラメトリックスタディによる設計空閒の網羅的な探查を比較した結果, EGO によって最適解 近傍領域の $C_{L}$ の予測が正しく行われていることが確認された.

・ パラメトリックスタディに対し非常に少ない実験回数で最適な駆動条件を探查することができ，本手法を用い ると試験コストを大幅に削減することができることが確認された。

本稿では最適化問題の例として，2 変数の最適化を行ったが, 複数のプラズマアクチュエータを設置する等, 問題に よっては飛躍的に設計変数が増加した場合には本最適化手法では大きなアドバンテージを持つため, 結果的に設計探査 によってプラズマアクチュエータの潜在性能を十分に評価することができると期待している.

\section{文献}

（1）藤井孝藏，松野隆，“DBD プラズマアクチュエーターバリア放電を利用した新しい流体制御技術”, 機械学会流体工学部門ニューズレター流れ，2007 年 8 月号, (2007).

(2) 松野隆，太田健太郎，川口幹祐，松尾好修，川添博光，“ブラフボディ後流制御におけるプラズマアクチュエータ の性能の周波数依存性”，第 48 回飛行機シンポジウム講演集 (2010), $1 \mathrm{D} 8$.

(3) Kanazaki, M., Yokokawa, Y., Murayama, M., Ito, T., Jeong, S., and Yamamoto, K., "Nacelle Chine Installation Based on Wind Tunnel Test Using Efficient Design Exploration," Transaction of Japan Society and Space Science, Vol.51, No. 173 (November 2008), pp. 146-150.

(4) Jeong, S., Murayama, M., and Yamamoto, K., "Efficient Optimization Design Method Using Kriging Model," Journal of Aircraft, Vol.42, No.2 (2005), p.p. 413-420. 